\title{
Tepki Yüzey Metodolojisi Kullanarak Alüminyum Matrisli Kompozitlerin Aşınma Parametrelerinin Optimizasyonu
}

\author{
Doğan ŞİMŞEK* \\ Milli Savunma Üniversitesi, Kara Astsubay Meslek Yüksekokulu, Otomotiv Teknolojileri Bölümü, Balıkesir \\ (ORCID: 0000-0002-5509-9314)
}

\begin{abstract}
$\ddot{O} \mathbf{z}$
$\mathrm{Bu}$ çalışmada, mekanik alaşımlama yöntemiyle üretilen alüminyum matrisli kompozitlerin aşınma performansı incelenmiştir. Tepki Yüzey Metodolojisi (TYM) Merkezi Birleşik Tasarım (MBT) kullanılarak belirli sürtünme katsayına bağlı olarak aşınma parametreleri optimize edilmeye çalışılmışıı. Farklı takviye miktarlarıyla (\%6 ve \%12) üretilen kompozit malzemelerin aşınma testleri farklı yük $(5 \mathrm{~N}, 10 \mathrm{~N}$ ve $20 \mathrm{~N})$ ve farklı kayma hızlarında $\left(0,2 \mathrm{~ms}^{-1}, 0,4 \mathrm{~ms}^{-1}\right.$ ve $\left.0,6 \mathrm{~ms}^{-1}\right)$ yapılmıştır. Aşınma test sonuçlarında, optimum aşınma parametrelerini belirlemek için ağılık kaybı (düşük en iyi) ve sürtünme katsayısı 0,54 (en iyi) yaklaşımı kullanılmıştır. Elde edilen sonuçlarda, ağırlık kaybı için en etkili parametrenin takviye miktarı ve kayma hızına kıyasla yük olduğu görülmüştür. Sürtünme katsayısı için ise yük ve kayma hızına kıyasla takviye miktarı en etkili parametre olduğu belirlenmiştir. Elde edilen optimum parametreler ise $9,24 \mathrm{~N}$ yük, $0,6 \mathrm{~ms}^{-1}$ kayma hızı ve $\% 12$ takviye miktarı olduğu belirlenmiştir. Çalışma sonucunda elde edilen parametreler kullanılarak yapılan aşınma testlerinde, ağırlık kaybı $8,536 \mathrm{mg}$, sürtünme katsayısı 0,522 olarak elde edilmiştir.
\end{abstract}

Anahtar kelimeler: Alüminyum matrisli kompozit, Aşınma, Sürtünme katsayısı, Tepki yüzey metodolojisi.

\section{Optimization of Wear Parameters of Aluminum Matrix Composites Using Response Surface Methodology}

\begin{abstract}
In this study, was investigated the wear performance of aluminium matrix composites produced by mechanical alloying method. Using the Response Surface Methodology (RSM) Central Composite Design (CCD), it was attempted to optimize the wear parameters depending on the specific friction coefficient. Wear testers of composite materials produced with different reinforcement amounts $(6 \%$ and $12 \%)$ were made at different loads $(5 \mathrm{~N}, 10 \mathrm{~N}$ and $20 \mathrm{~N})$ and different sliding speeds $\left(0.2 \mathrm{~ms}^{-1}, 0.4 \mathrm{~ms}^{-1}\right.$ and $\left.0.6 \mathrm{~ms}^{-1}\right)$. In the wear test results, were used weight loss (low best) and friction coefficient 0.54 (best) approach to determine optimum wear parameters. The results show that the most effective parameter for weight loss is the reinforcement amount and the load compared to the sliding speed. For the friction coefficient, it was determined that the most effective parameter the reinforcement amount compared to the load and sliding speed. The optimum parameters obtained were determined to be $9.24 \mathrm{~N}$ load, $0.6 \mathrm{~ms}^{-1}$ sliding speed and $12 \%$ reinforcement amount. In the wear tests performed using the parameters obtained as a result of the study, the weight loss was found to be $8.536 \mathrm{mg}$ and the friction coefficient as 0.522 .
\end{abstract}

Keywords: Aluminium matrix composite, Wear, Friction coefficient, Response surface metodology.

\section{Giriş}

Alüminyum Matrisli Kompozit (AMK)'ler alüminyum ve alaşımlarına mukavemet kazandırmak amacıyla yapısında in-situ ve ex-situ olarak sert ikinci faz parçacık takviyeleri ile meydana gelirler. Parçacık takviyeli AMK'ler geleneksel alüminyum ve alaşımlarına kıyasla daha yüksek mukavemet, yüksek elastisite modülü, yüksek sertlik, yüksek elektriksel ve termal iletkenlik, oksitlenme ve aşınma direnci gibi özelliklere sahiptirler. AMK'ler sağladıkları bu avantajları nedeniyle havacılık ve otomotiv

*Sorumlu yazar: dsimsek@msu.edu.tr

Geliş Tarihi: 18.05.2021, Kabul Tarihi: 28.07.2021 
başta olmak üzere savunma sanayi ve birçok endüstriyel alanda yaygın olarak kullanılmaktadırlar. Özellikle otomotiv sektöründe, AMK'ler hafif olması nedeniyle ağırlığın azaltılması yönündeki çalışmaları desteklerken, aynı zamanda yüksek sıcaklık uygulamalarında da (piston ve silindir kapakları gibi) kullanılmaktadırlar [1, 2]. Bu kullanım alanlarının yanı sıra iyi aşınma direncine sahip AMK'ler aynı zamanda otomotiv ve hava araçlarının fren disk ve kampanalarında da yaygın bir şekilde kullanılmaktadır. Al matrise ilave edilen sert takviye parçacıkları, AMK malzemelerin aşınma direncinin artmasıyla birlikte çalışma sıcaklığı aralığını da genişletmektedir [3]. Otomotiv fren disk ve kampanalarda çalışma sırasında açığa çıkan ısı nedeniyle yükselen sıcaklıklarda aşınma direncinin yanı sıra sürtünme kararlılığı da önem arz etmektedir. Bu nedenle, yüksek sıcaklıklarda iyi aşınma direnciyle birlikte kararlı bir sürtünme katsayısı istenmektedir [4].

Araştırma çalışmalarının miktarını azaltmak, seri çalışmaları gerçekleştirmek ve zamanı daha uygun kullanmak için Tepki Yüzey Metodolojisi (TYM) yaygın olarak kullanılmaktadır. En uygun yanıt ve optimum değerler, TYM aracılı̆̆ıyla, Merkezi Birleşik Tasarım (MBT) sınırlı sayıda deneysel çalışmadan kolayca elde edilebilir. TYM, tek faktörlü deneysel tasarıma kıyasla deneyin mümkün olan en az çalışmasıyla en iyi optimal reaksiyon koşullarını sağlamak için istatistiksel ve matematiksel teknikler kullanır [5, 6] Danappa vd., [7] aşınma parametrelerinin ve farklı $\mathrm{TiO}_{2}$ miktarının etkisini TYM ile incelemişlerdir. Elde ettikleri sonuçlarda $\mathrm{TiO}_{2}$ miktarının uygulanan yüke göre aşınma oranını daha fazla etkilediğini belirtmişlerdir. Dewangan vd., [8] yaptıkları çalışmalarında A356/TiB 2 in-situ kompozitlerin yük kayma hızı ve kayma mesafesi parametrelerinin optimizasyonu için TYM kullanmışlardır. Elde ettikleri aşınma oranı sonuçlarının in-situ $\mathrm{TiB}_{2}$ parçacıklarından önemli ölçüde etkilendiğini belirtmişlerdir. Bunun yanı sıra ANOVA sonuçları tahmin edilen modelin aşınma oranını tahmin etmede önemli olduğunu rapor etmişlerdir. Aşınma oranının, uygulanan yükten ve ardından kayma mesafesinden büyük ölçüde etkilendiğini belirtmişlerdir. Ayrıca hız parametresinin aşınma oranının hesaplanmasında önemsiz bir parametre olduğunu bildirmişlerdir.

Yapılan bu çalışmada, sürtünme malzemesi olarak tasarlanan alüminyum matrisli kompozit malzemeler, farklı miktarlarda $\mathrm{ZrO}_{2}$ ilave edilerek mekanik alaşımlama yöntemiyle üretilen AMK'lerin farklı kayma hızı ve yük altında ağırlık kaybı ve sürtünme katsayısı sonuçları incelenmiştir. Elde edilen ağırlık kaybı ve sürtünme katsayısı sonuçları değerlendirilerek optimum takviye miktarı ve optimum aşınma parametrelerinin belirlenmesi hedeflenmiştir. Aşınma parametrelerinin optimizasyonu için sürtünme katsayısı dikkate alınarak tepki yüzey metodolojisi yöntemiyle incelenmiştir.

\section{Materyal ve Metot}

\subsection{AMK’lerin Üretimi}

Deneysel çalışmalarda ticari saflıkta $0-50 \mu \mathrm{m}$ alüminyum tozu matris malzemesi olarak kullanılmıştır. Matrise kat1 yağlayıcı olarak \%2 grafit ilave edilmiştir. Takviye malzemesi olarak 0-10 $\mu$ m parçacık boyutunda $\mathrm{ZrO}_{2}$ kullanılmıştır. Hacimsel olarak içerisinde $\% 2$ grafit ilave edilerek hazırlanan matrise, yine hacimsel olarak 2 farklı oranda (\%6, ve \%12) $\mathrm{ZrO}_{2}$ ilave edilmiştir. Belirlenen miktarlarda hazırlanan tozlar planeter tip değirmende $60 \mathrm{dk}$ mekanik alaşımlanmıştır. Mekanik alaşımlama (MA) sırasında tozların aşırı ısınmasını önlemek için tozlar $30 \mathrm{dk}$ alaşımlanmış, $15 \mathrm{dk}$ durdurularak soğuması sağlanmıştır. Mekanik alaşımlama işleminde, paslanmaz çelik ögütme hücresi, $10 \mathrm{~mm}$ 'lik bilyalar ve 10:1 bilya toz oranı kullanılmıştır. MA sırasında tozların topaklanmasını önlemek amacıyla İşlem Kontrol Kimyasalı (IKK) olarak $1 \mathrm{ml}$ metanol kullanılmıştır. MA tozlar tek eksenli preste soğuk şekillendirilerek (700 MPa) Ø10x8 mm ölçülerinde ham numuneler üretilmiştir. Soğuk şekillendirme sırasında olası kalıp ve numune deformasyonunu önlemek amacıyla kalıp içi yağlayıcısı olarak çinkostearat kullanılmıştır. Üretilen ham numuneler $600{ }^{\circ} \mathrm{C}$ sicaklıkta $120 \mathrm{dk}$ sinterlenmiş ve firın içerisinde oda sıcaklığına soğuması için beklenmiştir. Yoğunluk ölçümleri Archimedes' prensibine göre yapılmıştır. Yoğunluk ölçümleri beş farklı numuneden yapılmış ve ortalama değer alınarak hesaplanmıştır. Sertlik ölçümleri Shimadzu mikro sertlik test cihazında (10 s süre ve yük HV2 uygulanarak) yapılmıştır. Sertlik ölçümleri beş farklı numuneden beş farklı̈ ölçüm noktasından alınarak ortalama değer hesaplanmıştır. 


\subsection{AMK'lerin Așınma Testleri}

Üretilen AMK'lerin aşınma testleri ASTM G77 standardına göre blok on ring aşınma test düzeneğinde yapılmıştır. Aşınma testlerinde üç farklı yük $(5 \mathrm{~N}, 10 \mathrm{~N}$ ve $20 \mathrm{~N})$ üç farklı kayma hızı $\left(0,2 \mathrm{~ms}^{-1}, 0,4 \mathrm{~ms}^{-}\right.$ ${ }^{1}$ ve $\left.0,6 \mathrm{~ms}^{-1}\right)$ kullanılmıştır. Testlerde kayma mesafesi olarak $94 \mathrm{~m}(120 \mathrm{~km} / \mathrm{h}$ hızdaki bir aracın güvenli durma mesafesi) kayma mesafesi kullanılmıştır. Aşınma testi öncesinde numune ve ring yüzeyi alkol ile temizlenmiştir. Aşınma testleri üç farklı numunede tekrar edilmiştir. Ağırlık kaybı ve sürtünme katsayısı değerleri ortalama alınarak hesaplanmıştır.

\subsection{AMK'lerin Tepki Yüzey Metodolojisi}

Tepki Yüzey Metodolojisi (TYM) alanı, ağırlık kaybı ve sürtünme katsayısının tahmin ve optimize etmek için kullanılmıştır. Bu tahmin ve optimizasyon için ampirik ilişkiler geliştirmek, yanıt ve süreç değişkenleri arasında uygun bir yakınlaştırma ilişkisi geliştirebilmek için sürecin alanını veya bağımsız değişkenleri ve ampirik istatistiksel modellemeyi oluşturmak için deneysel stratejiden oluşmaktadır. AMK'lerin ağırlık kaybı ve sürtünme katsayısı sonuçlarını doğrudan etkileyen parametreler yük (A), kayma hızı (B) ve takviye miktarı (C) tanımlanmıştır. Bu çalışma kapsamında yanıt yüzeyini (Y) belirtmek için faktörler ve yanıtlar arasındaki matematiksel ilişkiyi formüle etmek için Eşitlik 3'te verilen ikinci dereceden polinom regresyon denklemi kullanılmıştır [9].

A ğırlık Kaybı $=f(A, B, C)$

Sürtünme Katsaylst $=f(A, B, C)$

$Y=b_{0}+\sum b_{i} x_{i}+\sum b_{i i} x_{i}^{2}+\sum b_{i j} x_{i} x_{j}+e_{r}$

Üç faktör için, seçilen polinom Eşitlik 4 ve 5'te verilen şekilde ifade edilebilir.

$$
\begin{gathered}
\begin{aligned}
\text { Ăgılı Kaybl }=b_{0}+ & b_{1}(A)+b_{2}(B)+b_{3}(C)+b_{11}(A A)+b_{22}(B B)+b_{33}(C C) \\
+ & b_{12}(A B)+b_{13}(A C)+b_{23}(B C)
\end{aligned} \\
\begin{aligned}
\text { Sürtünme Katsayısl }= & b_{0}+b_{1}(A)+b_{2}(B)+b_{3}(C)+b_{11}(A A)+b_{22}(B B)+b_{33}(C C) \\
& +b_{12}(A B)+b_{13}(A C)+b_{23}(B C)
\end{aligned}
\end{gathered}
$$

Burada, b0 cevapların ortalamasıdır ve b1, b2. . .b23, parametrelerin ilgili ana ve etkileşim etkilerine bağlı katsayılardır.

Farklı miktarlarda $\mathrm{ZrO}_{2}$ ilave edilen AMK'lerin ağırlık kaybı ve sürtünme katsayısının matematiksel modellenmesi ve optimizasyonu için MINITAB 17 yazılımı kullanılmıştır. Deneyler üç seviyeli seçilen üç faktöre göre tasarlanmış ve Tablo 1'de verilmiştir. Aşınma testleri sonrasında elde edilen ağırlık kaybı ve sürtünme katsayısı sonuçları birleştirilmiş ve Tablo 2' de cevap olarak verilmiştir. Deney tasarımı Merkezi Birleşik Tasarım (MBT) kullanılarak üç seviyeli tam faktöriyel L20 için çizilmiştir. Yük, kayma hızı ve takviye miktarı gibi bağımsız faktörlere göre farklı miktarlarda $\mathrm{ZrO}_{2}$ takviyeli AMK'lerin ağırlı kaybı ve sürtünme katsayısı yanıtlarını göstermektedir. Yanıtları tanımlamak için etkileşim grafikleri çizilmiştir. Grafikler bağımsız değişkenlerin çeşitli kombinasyonlarına dayanmaktadır. Optimizasyon, ağırlık kaybı için "en düşük en iyi” şeklinde tanımlanmıştır. Sürtünme katsayısı için optimizasyon 0,540 değerleri optimum şeklinde tanımlanmıştır. Optimizasyon için kullanılan sürtünme katsayısı değerleri "Karayolu Taşıtları için Fren SistemleriBalatalar-Sürtünme Frenleri Standartları" (Standards for Road Vehicles-Brake Systems-Pads-Friction Brakes) TSE 555 (TSE 555, 1992) [10] ve "Fren Balataları için Sürtünme Katsayısı Tanımlama ve Çevresel İşaretleme Sistemi" (Friction Coefficient Identification and Environmental Marking System for Brake Linings) SAE J866 (SAE J866, 2012) [11] standartlarında sinıflandırılan balataların sürtünme katsayısı standartlarının en yüksek değerine göre belirlenmiştir. Böylece en düşük ağırlık kaybı ve belirtilen sürtünme katsayısı değerlerine sahip parametreler optimum olarak kabul edilir. 
Tablo 1. Aşınma parametrelerinin giriş seviyeleri

\begin{tabular}{clccc}
\hline S No & Parametreler & $\mathbf{- 1}$ & $\mathbf{0}$ & $\mathbf{1}$ \\
\hline A & Yük (N) & 5 & 10 & 20 \\
B & Kayma hızı $\left(\mathrm{ms}^{-1}\right)$ & 0,2 & 0,4 & 0,6 \\
C & Takviye miktarı (\%) & 0 & 6 & 12 \\
\hline
\end{tabular}

Tablo 2. Bağımsız değişkenler için analitik yanıt tablosu

\begin{tabular}{cccccc}
\hline Sıra & $\mathbf{A}$ & $\mathbf{B}$ & $\mathbf{C}$ & Ağırlı kaybı & Sürtünme katsayıSı \\
\hline $\mathbf{1}$ & 1 & 1 & 1 & 13,1 & 0,598 \\
$\mathbf{2}$ & 1 & -1 & -1 & 22,6 & 0,555 \\
$\mathbf{3}$ & -1 & 1 & -1 & 13,5 & 0,462 \\
$\mathbf{4}$ & 0 & 0 & 0 & 16,3 & 0,557 \\
$\mathbf{5}$ & -1 & -1 & 1 & 8,0 & 0,420 \\
$\mathbf{6}$ & 0 & 0 & 0 & 16,3 & 0,557 \\
$\mathbf{7}$ & -1 & -1 & -1 & 14,0 & 0,458 \\
$\mathbf{8}$ & 0 & 0 & 0 & 16,3 & 0,557 \\
$\mathbf{9}$ & 0 & 0 & 0 & 16,3 & 0,557 \\
$\mathbf{1 0}$ & -1 & 1 & 1 & 8,6 & 0,453 \\
$\mathbf{1 1}$ & 1 & -1 & 1 & 13,4 & 0,532 \\
$\mathbf{1 2}$ & 1 & 1 & -1 & 19,3 & 0,618 \\
$\mathbf{1 3}$ & 0 & 0 & -1 & 19,4 & 0,562 \\
$\mathbf{1 4}$ & 0 & 1 & 0 & 16,0 & 0,576 \\
$\mathbf{1 5}$ & 0 & -1 & 0 & 16,4 & 0,567 \\
$\mathbf{1 6}$ & 1 & 0 & 0 & 23,9 & 0,617 \\
$\mathbf{1 7}$ & 0 & 0 & 0 & 16,3 & 0,557 \\
$\mathbf{1 8}$ & 0 & 0 & 1 & 10,8 & 0,554 \\
$\mathbf{1 9}$ & -1 & 0 & 0 & 10,6 & 0,479 \\
$\mathbf{2 0}$ & 0 & 1 & 0 & 16,0 & 0,576 \\
\hline
\end{tabular}

\section{Bulgular ve Tartışma}

\subsection{Sertlik ve Așınma Sonuçları}

Şekil 1'de verilen mekanik alaşımlama yöntemiyle üretilen AMK'lerin sertlik sonuçları incelendiğinde, matris içerisinde artan takviye miktarı ile sertliğin arttığı görülmektedir. En yüksek sertlik değeri \%12 $\mathrm{ZrO}_{2}$ ilave edilen AMK malzemede $(878 \mathrm{HV})$ elde edilirken, en düşük sertlik matris malzemesinde (689 HV) elde edilmiştir. Elde edilen sonuçlar beklenen bir durumdur. Matrise ilave edilen sert oksit parçacıkları matrisin plastik deformasyona karşı direncini artırmaktadır. Matrisin plastik deformasyona karşı direncinin artması kompozit malzemelerin sertlik değerini artırmaktadır [12].

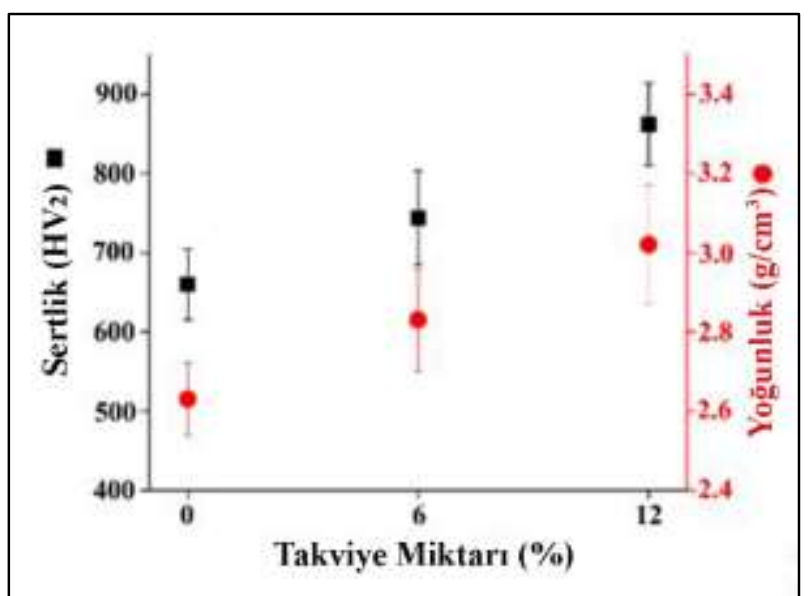

Şekil 1. Mekanik alaşımlama yöntemiyle üretilen AMK'lerin sertlik ve yoğunluk sonuçları

Yine Şekil 1'de verilen yoğunluk değişimleri incelendiğinde, matris içerisinde artan takviye miktarıyla yoğunluk değerlerinin arttı̆̆ görülmektedir. En düşük yoğunluk değeri matris malzemesinde $(2,69$ 
$\mathrm{g} / \mathrm{cm}^{3}$ ) olarak elde edilirken, en yüksek yoğunluk değeri $\% 12 \mathrm{ZrO}_{2}$ ilave edilen kompozit malzemede $\left(3,06 \mathrm{~g} / \mathrm{cm}^{3}\right)$ olarak elde edilmiştir. Yoğunluğun artması beklenen bir durumdur. Takviye olarak kullanılan $\mathrm{ZrO}_{2}$ 'nin yoğunluğunun $\mathrm{Al}^{\prime}$ 'un yoğunluğundan yüksek olması yoğunluk artışının temel nedenidir. Daha önce yapılan çalışmalarda da benzer sonuçların elde edildiği raporlanmıştır [13-15]. Mekanik alaşımlama yöntemiyle üretilen AMK'lerin farklı yük altında ve farklı kayma hızlarındaki ağırlık kaybı sonuçları Şekil 2'de verilmiştir.

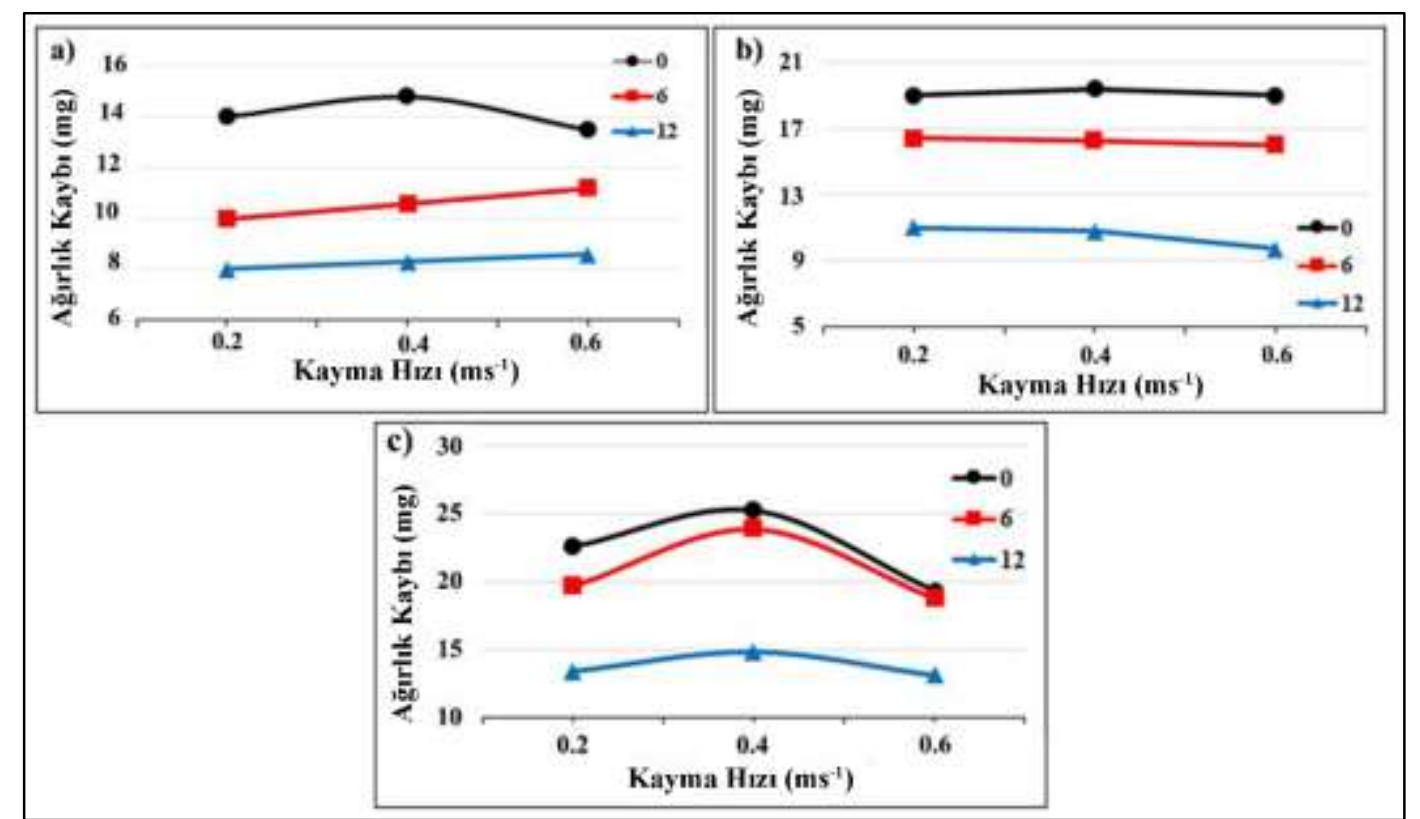

Şekil 2. Üretilen kompozit malzemelerin farklı yükler altındaki ağırlık kaybı sonuçları a) $5 \mathrm{~N}$, b) $10 \mathrm{~N}$ ve c) $20 \mathrm{~N}$

Şekil 2'de verilen mekanik alaşımlama yöntemiyle üretilen AMK'lerin ağırlık kaybı sonuçları incelendiğinde bütün yüklerde artan takviye miktarı ile ağırlık kaybının azaldığı görülmektedir. Bununla birlikte artan yük ile ağırlık kaybının arttığı anlaşılmaktadır. En düşük ağırlık kaybı \%12 $\mathrm{ZrO}_{2}$ ilave edilen AMK malzemede $5 \mathrm{~N}$ yük altında $0,2 \mathrm{~ms}^{-1}$ kayma hızında, en yüksek ağırlık kaybı matris malzemesinde $20 \mathrm{~N}$ yük altında $0,4 \mathrm{~ms}^{-1}$ kayma hızında elde edilmiştir. AMK malzemelerde aşınma direnci genel olarak sertlikle doğru orantılı olarak artmaktadır. Sertliği yüksek olan AMK malzemelerde aşınma direnci yüksektir. Ay vd. [14] yaptıkları bir çalışmada, artan takviye miktarı ile ağırlık kaybının azaldığını belirtmişlerdir. Bununla birlikte, elde ettikleri ağırlık kaybı ve sertlik sonuçları arasındaki ilişkiyi açık bir şekilde gösterdiğini rapor etmişlerdir. Ağırlık kaybı sonuçlarında, artan yük ile bütün takviye oranlarında ağırlık kayıplarının arttı̆̆ı görülmektedir. Artan yük ile birlikte takviye parçacıklarının etrafında gerilme yığılması oluşmaktadır. Oluşan bu gerilme yığılması ile birlikte, sünek matriste çatlak oluşumları meydana gelmekte ve oluşan bu mikro çatlaklar sert parçacıkların matris ile bağının zayıflamasına neden olmaktadır. Sert takviye fazı ile matris arasındaki mekanik bağlarda (ara yüzeylerde) meydana gelen zayıflıklara bağlı olarak oluşan kırılmalar, ağırlık kaybının artmasına neden olmaktadır. Bununla birlikte kayma hızının artmasıyla ağılık kaybının azalması beklenmektedir. Kayma hızının artmasıyla sürtünmeden kaynaklı açığa çıkan ısının artması yüzeyde daha etkili (koruyucu) bir oksit tabakası oluşmasına neden olmaktadır. Oluşan oksit tabakasının katı yağlayıcı özelliğinden dolayı ağırlık kaybının azalmasına neden olmaktadır [16, 17]. Elde edilen ağırlık kaybı sonuçları incelendiğinde $10 \mathrm{~N}$ yük altında elde edilen sonuçlarda kısmen bu beklentiyi karşılamaktadır. Ancak $5 \mathrm{~N}$ ve $20 \mathrm{~N}$ yük altında elde edilen sonuçlarda ise bu beklentiyi sağlamadığ görülmektedir. Düşük yük altında $(5 \mathrm{~N})$ ağırlık kaybı takviye malzemesi ilave edilen kompozit malzemelerde artan kayma hızıyla artma eğiliminde olduğu görülmektedir. Artan kayma hızı ile numune yüzeyinden kopan parçacıkların tribolojik sistemden uzaklaşırken yüzeyden daha fazla parça kopararak uzaklaşması ağırlık kaybının artmasına neden olmaktadır. Yüksek yüklerde $(20 \mathrm{~N})$ ağırlık kaybı 0,4 $\mathrm{ms}^{-1}$ kayma hızında artarken $0,6 \mathrm{~ms}^{-1}$ kayma hızında tekrardan azaldığı görülmektedir. $0,4 \mathrm{~ms}^{-1}$ kayma hızındaki bu ağırlık kaybı artışı, yükün etkisi ile numune yüzeyindeki gerilmelere bağlı olarak numune yüzeyinde oluşan koruyucu oksit tabakasının kırılması ile açıklanabilir. Daha önce yapılan bir çalışmada benzer sonuçlar 
rapor edilmiş̧ir [18]. Mekanik alaşımlama yöntemiyle üretilen AMK'lerin farklı yük altında ve farklı kayma hızlarındaki sürtünme katsayısı Şekil 3’te verilmiştir.

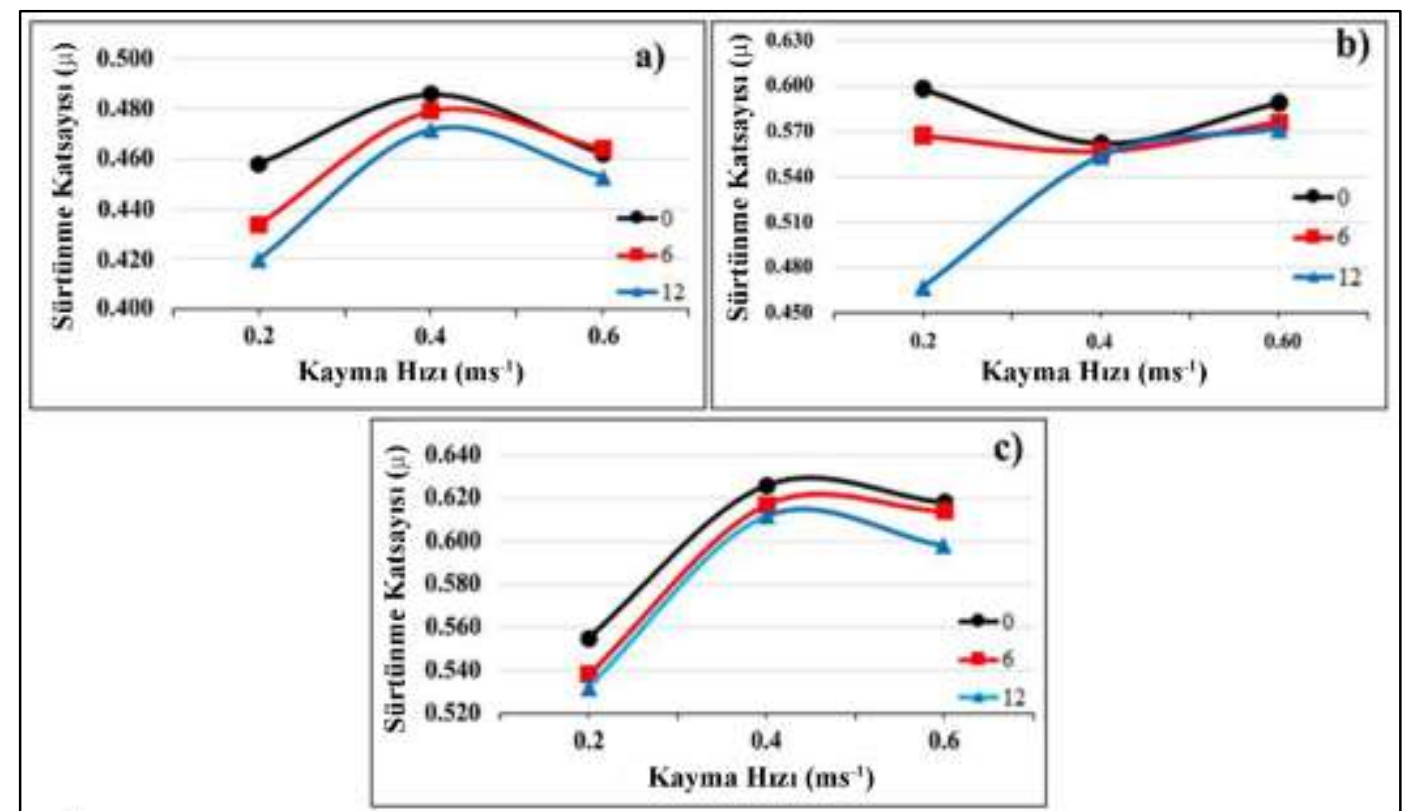

Şekil 3. Üretilen kompozit malzemelerin farklı yükler altındaki sürtünme katsayısı sonuçları a) 5N, b) $10 \mathrm{~N}$ ve c) $20 \mathrm{~N}$

Şekil 3'te verilen mekanik alaşımlama yöntemiyle üretilen AMK'lerin sürtünme katsayıs1 sonuçları incelendiğinde artan takviye miktarı ile sürtünme katsayısının azaldığı görülmektedir. Bununla birlikte artan yük ile sürtünme katsayısının arttığı anlaşılmaktadır. En düşük sürtünme katsayısı $\% 12$ $\mathrm{ZrO}_{2}$ ilave edilen AMK malzemede $5 \mathrm{~N}$ yükte, en yüksek sürtünme katsayısı matris malzemesinde 20 $\mathrm{N}$ yükte elde edilmiştir. Matris içerisinde artan takviye miktarı AMK malzemenin sertliğini artırmakta ve sürtünme katsayısının azalmasına neden olmaktadır. Artan yük ile birlikte sürtünme katsayılarının arttığı görülmektedir. Artan yük ile numune yüzeyinde oluşan kırılmalar ve dökülmeler yüzey pürüzlülüğünün artmasına neden olmaktadır. Sonuç olarak, artan yüzey pürüzlülüğü sürtünme katsayısını artırmaktadır. Daha önce yapılan çalışmalarda benzer sonuçlar rapor edilmiştir $[16,19]$. Bununla birlikte en yüksek sürtünme katsayısı $5 \mathrm{~N}$ ve $20 \mathrm{~N}$ yük altında $0,4 \mathrm{~ms}^{-1}$ kayma hızında elde edildiği görülmektedir. Kayma hızının $0,6 \mathrm{~ms}^{-1}$ olmasıyla sürtünme katsayısının tekrardan azaldığ görülmektedir. Sürtünme katsayısındaki bu azalma eğilimi aşınma yüzeyinde oluşan oksit tabakasından kaynaklanmaktadır. Yüzeyde oluşan bu oksit tabakasının koruyucu etkisi ve katı yağlayıcı olarak görev yapması sürtünme katsayısının azalmasına neden olmaktadır [19]. 0,4 $\mathrm{ms}^{-1}$ kayma hızında sürtünme katsayısının artması aşınma sırasında numune yüzeyinden kopan iri bir parçacıktan kaynaklandığ düşünülmektedir. Şekil 2'de verilen ağırlık kaybı sonuçları bu durumu desteklemektedir. Aşınma sırasında numune yüzeyinden kopan iri parçacıkların ağırlık kaybının artmasına neden olurken aynı zamanda numunenin yüzey pürüzlülügünü arttırarak sürtünme katsayısının artmasına neden olmaktadır.

\subsection{TYM ve Optimizasyon Sonuçları}

Verilerin normalliği, normal olasılık grafiği ile değerlendirilmiştir. Ağırlık kaybı ve sürtünme katsayıları için artıkların normal olasılık grafiği sırasıyla Şekil 4.a ve b'de verilmiştir. 


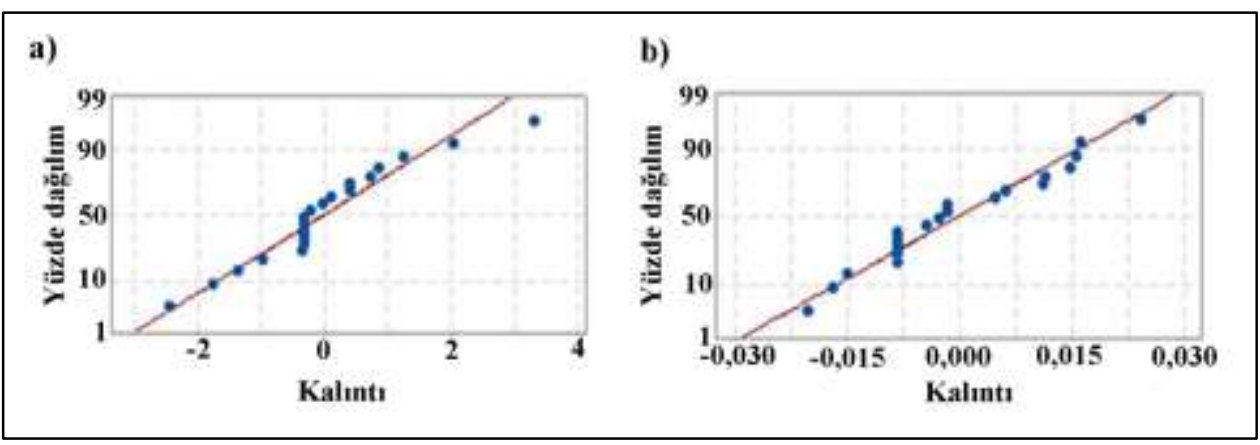

Şekil 4. Normal olasılık grafiği a) Ağırlık kaybı, b) Sürtünme Katsayısı

Şekil 4'te verilen ağırlık kaybı ve sürtünme katsayısı için verilerin normalliği incelendiğinde artıkların düz bir çizgide dağıldığ 1 görülmektedir. $\mathrm{Bu}$, hataların normal şekilde dağıtıldığı anlamına gelmektedir. Artıklar arasında çizilen grafikle test edilen verilerin bağımsızlık analizi Şekil 5.a ve b'de verilmiştir.

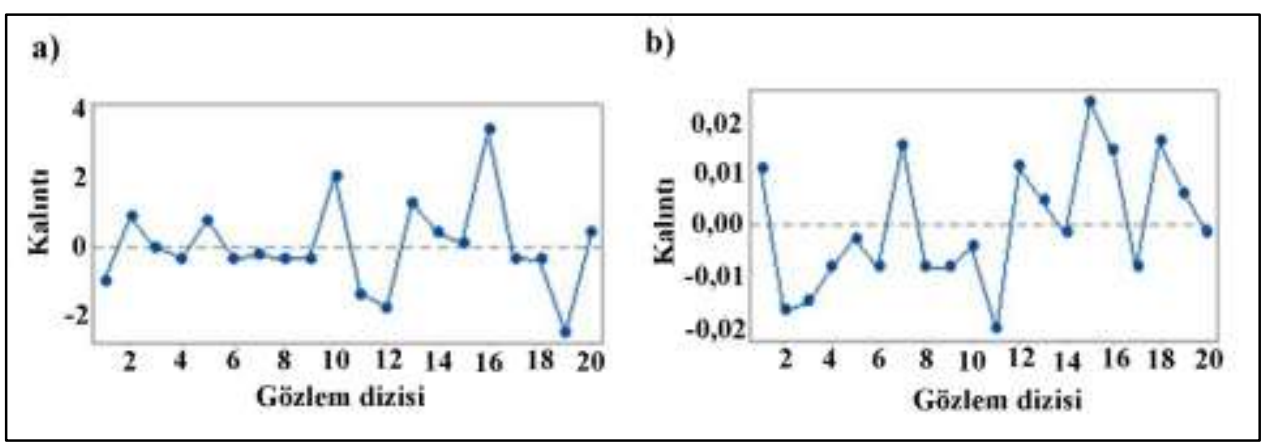

Şekil 5. Verilerin bağımsızlık dağılımı a) Ağırlık kaybı, b) Sürtünme katsayısı

Şekil 5'te verilen ağırlık kaybı ve sürtünme katsayısı için verilerin bağımsızlık analizi incelendiğinde, aşınma testlerinde elde edilen ağırlık kaybı ve aşınma oranı için çalışma sırası, tüm çalışma kalıntıları, seviyelerin üzerinde ya da arasında olduğu görülmektedir. Elde edilen analiz sonuçları tahmin edilebilir bir örüntünün gözlenmediğini doğrulamaktadır. Ağırlık kaybı ve sürtünme katsayıları için tahmini regresyon katsayıları sırsıyla Tablo 3 ve Tablo 4 'te verilmiştir.

Tablo 3. A ğırlık kaybı için tahmini regresyon katsayıları

\begin{tabular}{lllll}
\hline Kaynak & Coefficient & SE Coefficient & T & P \\
\hline Constant & 18,022 & 0,634 & 28,45 & 0,000 \\
Yük & 3,760 & 0,502 & 7,49 & 0,000 \\
Kayma hızı & $-0,392$ & 0,487 & $-0,80$ & 0,440 \\
Takviye miktarı & $-3,522$ & 0,503 & $-7,00$ & 0,000 \\
Yük*Yük & $-1,19$ & 1,06 & $-1,12$ & 0,288 \\
Kayma hızı* Kayma hızı & $-0,706$ & 0,870 & $-0,81$ & 0,436 \\
Takviye miktarı* Takviye miktarı & $-1,957$ & 0,930 & $-2,10$ & 0,062 \\
Yük* Kayma hızı & $-0,478$ & 0,554 & $-0,86$ & 0,408 \\
Yük* Takviye miktarı & $-0,484$ & 0,555 & $-0,87$ & 0,404 \\
Kayma hizı* Takviye miktarı & 0,513 & 0,561 & 0,91 & 0,383 \\
\multicolumn{1}{c}{$\quad$ S= 1,58753 } & R-sq $=92,15 \%$ & & R-sq(adj) $=85,09 \%$ \\
\hline
\end{tabular}

Tablo 3’te ağırlık kaybı için tahmini regresyon katsayıları verilmiştir. Tabloda ağırlık kaybını etkileyen parametreleri göstermektedir ve ağırlık kaybını etkileyen parametrelerin tahmini etkilerini göstermektedir. Ağırlık kaybının tahmini regresyon denklemi Eşitlik 6'da verilmiştir. Tablo 3 'te üretilen AMK'lerin aşınma testlerinde ağırlık kaybı için kayma hızı ve takviye oranına kıyasla en etkili parametrenin yük olduğunu göstermektedir. Geliştirilen modelin önemi, Varyans Analizi (ANOVA) tekniği kullanılarak test edilmiştir. Tespit katsayısı $\left(\mathrm{R}^{2}\right)$ modelin uyum iyiliğini göstermektedir [20]. Varyans Analizinden elde edilen tespit katsayısı değeri $\left(R^{2}=0.921\right)$ toplam varyansın sadece \%10'undan 
azının model tarafından açıklanamadığını göstermektedir. Düzeltilmiş tespit katsayısının (düzeltilmiş $\mathrm{R}^{2}=0.850$ ) değeri yüksektir. Düzeltilmiş tespit katsayısının yüksek değeri modelin yüksek önemini göstermektedir.

Ağırlık Kaybı $=18.022+3.760$ Yük -0.392 Kayma hızı -3.522 Takviye miktarı -1.19 Yük

* Yük - 0.706 Kayma hızı * Kayma hızı - 1.957 Takviye miktarı *

Takviye miktarı -0.478 Yük * Kayma hızı -0.484 Yük

* Takviye miktarı + 0.513 Kayma hız1 * Takviye miktarı

Tablo 4. Sürtünme katsayısı için tahmini regresyon katsayıları

\begin{tabular}{lllll}
\hline Kaynak & Coefficient & SE Coefficient & T & P \\
\hline Constant & 0,59337 & 0,00497 & 119,41 & 0,000 \\
Yük & 0,06480 & 0,00394 & 16,46 & 0,000 \\
Kayma hızı & 0,01838 & 0,00382 & 4,81 & 0,001 \\
Takviye miktarı & $-0,00980$ & 0,00395 & $-2,48$ & 0,032 \\
Yük*Yük & $-0,05605$ & 0,00834 & $-6,72$ & 0,000 \\
Kayma hız* Kayma hızı & $-0,00443$ & 0,00682 & $-0,65$ & 0,531 \\
Takviye miktarı* Takviye miktarı & $-0,01822$ & 0,00729 & $-2,50$ & 0,032 \\
Yük* Kayma hızı & 0,01229 & 0,00434 & 2,83 & 0,018 \\
Yük* Takviye miktarı & 0,00002 & 0,00435 & 0,00 & 0,997 \\
Kayma hızı* Takviye miktarı & 0,00400 & 0,00440 & 0,91 & 0,385 \\
\multicolumn{1}{c}{ S= 0,0209878 } & R-sq =97,40\% & & R-sq(adj) & $=95,06 \%$ \\
\hline
\end{tabular}

Tablo 4'te sürtünme katsayısı için tahmini regresyon katsayıları verilmiştir. Tabloda sürtünme katsayısını etkileyen parametreleri göstermektedir ve sürtünme katsayısını etkileyen parametrelerin tahmini etkilerini göstermektedir. Sürtünme katsayısı için tahmini regresyon denklemi Eşitlik 7'de verilmiştir. Tablo 4'te aşınma testlerinde sürtünme katsayısı için kayma hızı ve yüke kıyasla en etkili parametrenin takviye miktarı olduğu anlaşılmaktadır. Sürtünme katsayısı için tespit katsayısı değeri $\left(\mathrm{R}^{2}=0.974\right)$ toplam varyansın \%5'inden daha azının açıklanamadığını göstermektedir. Düzeltilmiş tespit katsayısının (düzeltilmiş $\mathrm{R}^{2}=0.950$ ) değerinin de yüksek olduğu görülmektedir. Düzeltilmiş tespit katsayısının yüksek değeri, tahmin edilen tespit katsayısı'nın $\left(\mathrm{R}^{2}\right)$ düzeltilmiş tespit katsayısı (düzeltilmiş $\mathrm{R}^{2}$ ) ile iyi bir uyum içinde olduğunu göstermektedir. Ağırlık kaybı için giriş parametrelerinden elde edilen karşılaştırılmalı etkileşim grafikleri Şekil 6'da verilmiştir.

Sürtünme Katsayısı $=0.59337+0,06480$ Yük $+0,01838$ Kayma hızı- 0,00980 Takviye miktarı $-0,05605$ Yük * Yük - 0,00443 Kayma hızı * Kayma hızı

$-0,01822$ Takviye miktarı * Takviye miktarı $+0,01229$ Yük

* Kayma hızı + 0,00002 Yük * Takviye miktarı + 0,00400

Kayma hızı * Takviye miktarı

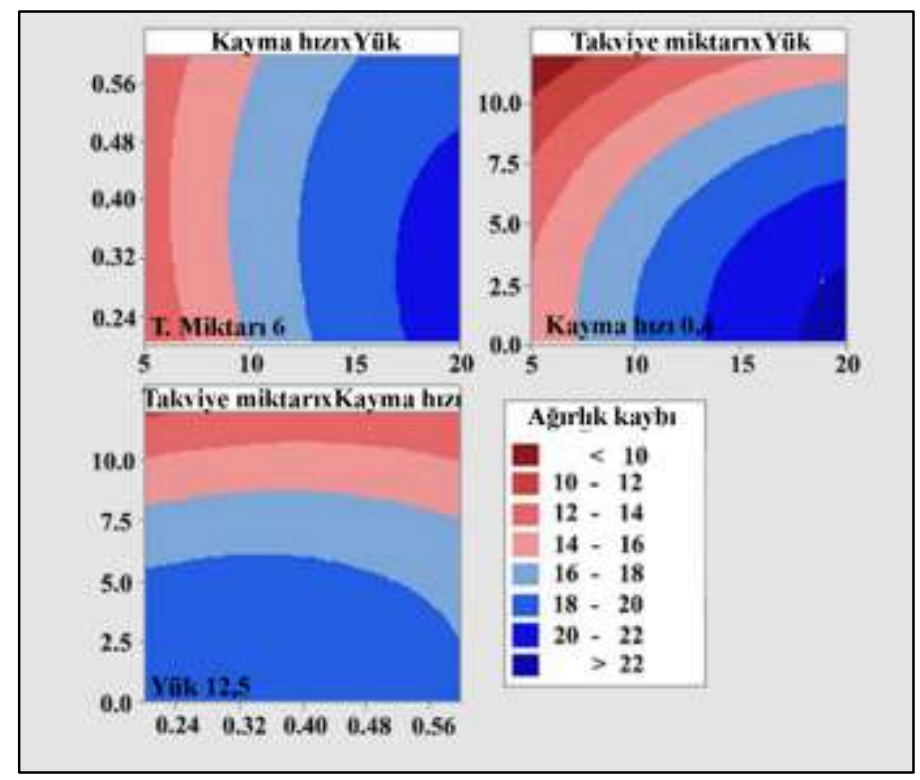

Şekil 6. Ağırlık kaybı etkileşim grafiğgi 
Şekil 6' da verilen ağırlık kaybı 2B etkileşim grafiği belirli bir yük, kayma hızı ve takviye miktarına göre belirlenmiştir. Elde edilen sonuçlar incelendiğinde $\% 6$ takviye ilave edilen kompozit malzemenin artan yükün, kayma hızından daha fazla etkili olduğu görülmektedir. Bununla birlikte 0,4 $\mathrm{ms}^{-1}$ kayma hızında takviye miktarı ve yükün etkili olduğu anlaşılmaktadır. Yükün artması ile ağırlık kaybının arttığ 1 , takviye miktarının artmasıyla bütün yüklerde ağırlık kaybının azaldığı anlaşılmaktadır. $12,5 \mathrm{~N}$ yük altında elde edilen $2 \mathrm{~B}$ etkileşim grafikte artan takviye miktarı ile ağırlık kaybının azalmasında etkisinin yüksek olduğu, kayma hızının takviye miktarına göre önemli bir etkisinin olmadığı anlaşılmaktadır. Sürtünme katsayısı için elde edilen etkileşim grafikleri Şekil 7'de verilmiştir.

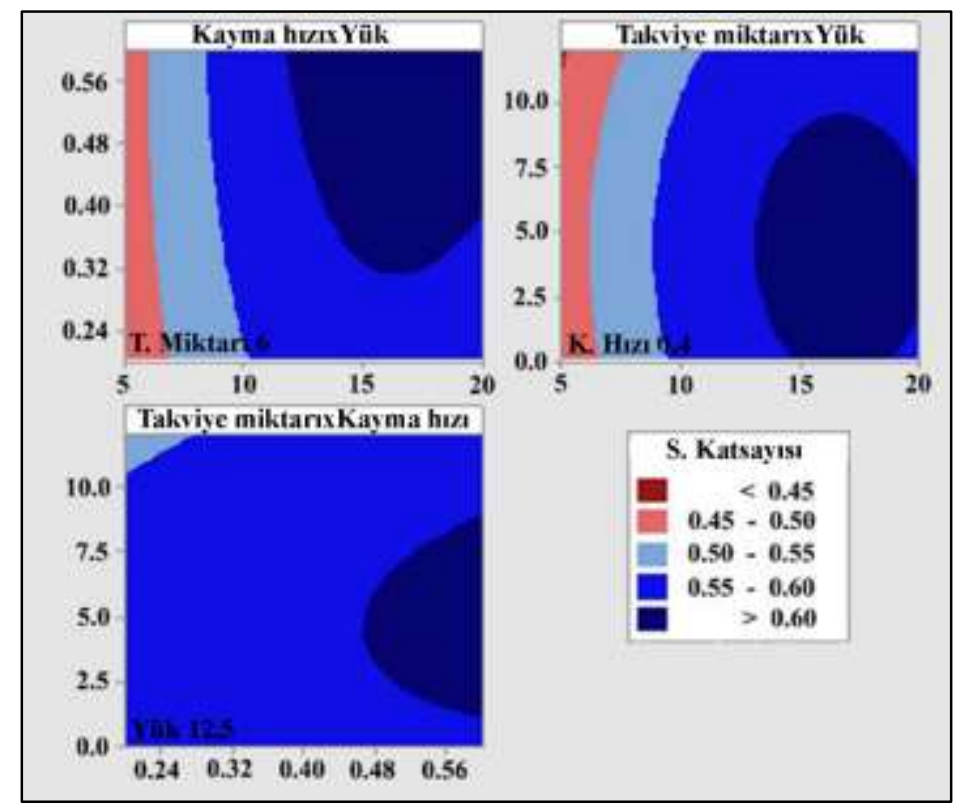

Şekil 7. Sürtünme katsayıs1 etkileşim grafiği

Şekil 7'de verilen sürtünme katsayıları 2B etkileşim grafiği belirli bir yük, kayma hızı ve takviye miktarına göre belirlenmiştir. Elde edilen sonuçlar incelendiğinde \%6 takviye ilave edilen kompozit malzemenin artan yük ile kayma hızının etkili olduğu görülmektedir. Yüksek kayma hızı ve yüksek yüklerde sürtünme katsayısının arttığı anlaşılmaktadır. Bununla birlikte $0,4 \mathrm{~ms}^{-1}$ kayma hızında takviye miktarı ile birlikte yükün etkili olduğu anlaşılmaktadır. Yükün artması ile sürtünme katsayısı artarken, takviye miktarının artmasıyla sürtünme katsayısının azaldığı anlaşılmaktadır. 12,5 N yük altında elde edilen 2B etkileşim grafiğinde, takviye miktarının sürtünme katsayısında önemli bir etkisinin olmadığı, yüksek kayma hızlarında belirli bir bölgede sürtünme katsayısının attığı görülmektedir. Ağırlık kaybı varyans analizi sonuçları Tablo 5'te verilmiştir.

Tablo 5. Ağırlık kaybı varyans analizi sonuçları

\begin{tabular}{lllllll}
\hline Source & DF & Seq SS & Adj SS & Adj MS & F & P \\
\hline Model & 9 & 295,887 & 295,887 & 32,876 & 13,04 & 0,000 \\
Linear & 3 & 241,297 & 266,399 & 88,800 & 35,23 & 0,000 \\
Square & 3 & 48,693 & 48,420 & 16,140 & 6,40 & 0,011 \\
Interaction & 3 & 5,896 & 5,896 & 1,965 & 0,78 & 0,532 \\
Residual Error & 10 & 25,203 & 25,203 & 2,520 & & \\
Lack-of-Fit & 5 & 25,203 & 25,203 & 5,041 & & \\
Pure Error & 5 & 0,000 & 0,000 & 0,000 & & \\
Total & 19 & 321,090 & & & & \\
\hline
\end{tabular}

Tablo 5'te verilen ağırlık kaybı için varyans analiz sonuçlarından ön görülen değerlerin elde edilen verilerle uyumlu olduğu anlaşılmaktadır. Ayrıca tabloda verilen p değerinin 0,05 'ten küçük olduğu görülmektedir. Geliştirilen modelin \%95 güven seviyesine sahip olduğunu doğrulamaktadır. Geliştirilen model gelecekteki uygulamalar için kullanılabilirdir. Ayrıca p değeri, F değerine göre daha düşüktür. Geliştirilen modelin yeterli olduğunu doğrulamaktadır. Punugupati vd.,[21] yaptıkları bir çalışmada p değerinin 0,05 ’ten küçük elde etmişlerdir. Elde edilen sonuçların önemli olduğunu ve güven 
seviyesinin yeterli olduğunu belirtmişlerdir. Sürtünme katsayısı varyans analizi sonuçları Tablo 6'da verilmiştir.

Tablo 6. Sürtünme katsayısı varyans analiz sonuçları

\begin{tabular}{lllllll}
\hline Source & DF & Seq SS & Adj SS & Adj MS & F & P \\
\hline Model & 9 & 0,058053 & 0,058053 & 0,006450 & 41,61 & 0,000 \\
Linear & 3 & 0,036866 & 0,046532 & 0,015511 & 100,05 & 0,000 \\
Square & 3 & 0,019816 & 0,019989 & 0,006663 & 42,98 & 0,000 \\
Interaction & 3 & 0,001370 & 0,001370 & 0,000457 & 2,95 & 0,085 \\
Error & 10 & 0,001550 & 0,001550 & 0,000155 & & \\
Lack-of-Fit & 5 & 0,001550 & 0,001550 & 0,000310 & $*$ & $*$ \\
Pure Error & 5 & 0,000000 & 0,000000 & 0,000000 & & \\
Total & 19 & 0,059603 & & & & \\
\hline
\end{tabular}

Tablo 6'da verilen sürtünme katsayısı varyans analizi sonuçları incelendiğinde, sürtünme katsayısı için $p$ değeri 0,05 'ten küçüktür. $P$ değerinin 0,05 ten küçük olması modelin istatistiksel olarak anlamlı olduğunu göstermektedir. Ayrıca modelin sürtünme katsayısı için modelin \%95 güven seviyesine sahip olduğu anlaşılmaktadır. Eşitlik 8'de verilen tespit katsayısı denklemi son derece güvenilir olduğu anlaşılmaktadır. Tablo 6'da verilen ve ANOVA testinden elde edilen $\mathrm{p}$ değerinin F değerinden küçük olduğu görülmektedir. Bu sonuç uygulanan işlemin anlamlı olduğunu dolayısıyla önerilen modelin doğru olduğunu göstermektedir. Daha önce yapılan çalışmalarda da benzer sonuçlar rapor edilmiştir [21-23].

\section{Sonuçlar}

Mekanik alaşımlama yöntemiyle üretilen $\mathrm{ZrO}_{2}$ takviyeli kompozit malzemelerin aşınma parametrelerinin optimizasyonu için yapılan çalışma sonucunda elde edilen sonuçlar aşağıda belirtilmiştir.

Üretilen kompozit malzemelerin aşınma testi sonuçlarında, matris içerisinde artan takviye miktarıyla ağırlık kaybının azaldığı görülmüsstür. En düşük ağılık kaybı bütün yüklerde $\% 12 \mathrm{ZrO}_{2}$ ilave edilen kompozit malzemede elde edilmiştir. $20 \mathrm{~N}$ yük altında elde edilen sonuçlarda kayma hızının artması $\left(0,4 \mathrm{~ms}^{-1}\right)$ ağırlık kaybının artmasına daha yüksek kayma hızlarında ise $\left(0,6 \mathrm{~ms}^{-1}\right)$ ağırlık kaybında azalma elde edilmiştir.

Sürtünme katsayıları sonuçlarında, sürtünme katsayısının artan kayma hızıyla arttığı, kayma hızının daha fazla artmasıyla sürtünme katsayılarında azalma olduğu görülmüştür. Özellikle düşük ve yüksek yükler altında ( $5 \mathrm{~N}$ ve $20 \mathrm{~N}$ ) kompozitlerin sürtünme katsayıları benzer davranışlar gösterdiği görülmüştür.

ANOVA testi sonucunda, ağırlık kaybı için düzeltilmiş tespit katsayısı (Adjust $\mathrm{R}^{2}=0,85$ ) olarak elde edilmiş, Sürtünme katsayısın sonuçlarında ise düzeltilmiş tespit katsayısı (Adjust $R^{2}=0,95$ olarak elde edilmişti. Elde edilen tespit katsayıları modelin önemli olduğunu göstermiştir.

Optimizasyon sonuçlarında, ağırlık kaybı için kayma hızı ve takviye oranı parametrelerine kıyasla yük parametresinin etkili olduğu, sürtünme katsayısı için ise kayma hızı ve yük parametresine kıyasla, takviye miktarının etkili olduğu görülmüştür. Elde edilen sonuçlarda optimum aşınma parametrelerinin $9,24 \mathrm{~N}$ yük, $0,6 \mathrm{~ms}^{-1}$ kayma hızı ve $\% 12$ takviye miktarı olduğu elde edilmiştir.

\section{Yazarların Katkısı}

Bu çalışmada tüm katkı yazara aittir.

\section{Çıkar Çatışması Beyanı}

Bu çalışmada yazarlar arasında herhangi bir çıkar çatışması bulunmamaktadır.

\section{Araştırma ve Yayın Etiği Beyanı}

Yapılan çalışmada araştırma ve yayın etiğine uyulmuştur. 


\section{Kaynaklar}

[1] Simsek D., Simsek İ., Ozyurek D. 2019. Production and characterization of Al-SiC composites by mechanical milling. Bitlis Eren Üniversitesi Fen Bilimleri Dergisi, 8 (1): 227-233.

[2] Rajabi M. 2003. Characterisation of Al-SiC composite materials produced by double pressingdouble sintering method. International Journal of Engineering Science, 14 (2): 21-37.

[3] Rajaram G., Kumaran S., Rao T. S., Kamaraj M. 2010. Studies on high temperature wear and its mechanism of $\mathrm{Al}-\mathrm{Si} /$ graphite composite under dry sliding conditions. Tribology International, 43 (11): 2152-2158.

[4] Etemoğlu A. B., Etemoğlu N., Türkan B., Canbolat, A. S. 2018. Araç fren sistemlerinin 1s11 performansının parametrik olarak incelenmesi. El-Cezeri Journal of Science and Engineering, 5 (2): 556-565.

[5] Asfaram A., Ghaedi M., Agarwal S., Tyagi I., Gupta V. K. 2015. Removal of basic dye Auramine- $\mathrm{O}$ by $\mathrm{ZnS}$ : $\mathrm{Cu}$ nanoparticles loaded on activated carbon: optimization of parameters using response surface methodology with central composite design. RSC Advances, 5 (24): 18438-18450.

[6] Yuan X., Liu J., Zeng G., Shi J., Tong,J., Huang G. 2008. Optimization of conversion of waste rapeseed oil with high FFA to biodiesel using response surface methodology. Renewable Energy, 33 (7): 1678-1684.

[7] Danappa G. T., Raghavendra C. R., Swamy R. P., Naik K. 2021. Dry sliding wear behaviour of Al7075/Gr/nano TiO2 MMC using RSM. Materials Today: Proceedings. 38 (5): 2797-2802.

[8] Dewangan S., Jha S. K., Mandal A. 2020. Optimization of dry sliding wear parameters of thixoformed A356-5TiB2 in-situ composites using RSM. Materials Today: Proceedings. 33 (8): 5061-5065.

[9] Saravanan I., Perumal A. E., Vettivel S. C., Selvakumar N., Baradeswaran A. 2015. Optimizing wear behavior of TiN coated SS 316L against Ti alloy using Response Surface Methodology. Materials \& Design, 67: 469-482.

[10] Road vehicles-Brake linings and pads for friction type brakes https://intweb.tse.org.tr/standard/standard/Standard.aspx? [Erişim Tarihi: 16 Nisan 2021].

[11] Friction Coefficient Identification and Environmental Marking System for Brake Linings J866_201207, https://www.sae.org/standards/content/j866_201207/ [Erişim Tarihi:16 Nisan 2021]

[12] Bharath V., Nagaral M., Auradi V., Kori S. A. 2014. Preparation of 6061Al-A12O3 MMC's by stir casting and evaluation of mechanical and wear properties. Procedia Materials Science, 6: 1658-1667.

[13] Simsek D., Özyürek D. 2020. The wear performance at elevated temperatures of aluminum matrix composite materials produced by mechanochemical method. Journal of Tribology, 142 (10): 101701.

[14] Ay H., Özyürek D., Yıldırım M., Bostan B. 2016. The effects of B4C amount on hardness and wear behaviours of 7075-B4C composites produced by powder metallurgy method. Acta Physica Polonica A, 129: 565-568.

[15] Baghchesara M. A., Abdizadeh H., Baharvandi H. R. 2010. Microstructure and mechanical properties of aluminum alloy matrix composite reinforced with $\mathrm{ZrO}_{2}$ particles. Asian Journal of Chemistry, 22 (5): 3824-3834.

[16] Özyürek D, Tekeli S, Güral A, Meyveci A, Gürü M. 2010. Effect of Al2O3 amount on microstructure and wear properties of $\mathrm{Al}-\mathrm{Al} 2 \mathrm{O} 3$ metal matrix composites prepared using mechanical alloying method. Powder Metallurgy and Metal Ceramics, 49 (5-6): 50-57.

[17] Özyürek D., Tunçay T., Kaya H. 2014. The effects of T5 and T6 heat treatments on wear behaviour of AA6063 alloy. High Temperature Materials and Processes, 33(3): 231-237.

[18] Özyürek D., Ciftci I., Tuncay T. 2013. The effect of aging and sliding speed on wear behaviour of $\mathrm{Cu}-\mathrm{Cr}-\mathrm{Zr}$ alloy. Wear Testing, 55 (6): 468-471.

[19] Simsek D., Simsek I., Ozyurek D. 2020. Relationship between A12O3 content and wear behavior of Al+ 2\% graphite matrix composites. Science and Engineering of Composite Materials, 27 (1): $177-185$. 
[20] Vettivel S. C., Selvakumar N., Narayanasamy R., Leema N. 2013. Numerical modelling, prediction of $\mathrm{Cu}-\mathrm{W}$ nano powder composite in dry sliding wear condition using response surface methodology. Materials \& Design, 50: 977-996.

[21] Punugupati, G., Kandi, K. K., Bose, P. S. C., Rao, C. S. P. 2018., Modeling and optimization of wear characteristics of gelcast fused silica ceramic composites using RSM. Materials Today: Proceedings, 5 (2): 6946-6953.

[22] Pugazhenthi, R., Sreeram, D., Scaria, C. T., Anbuchezhiyan, G., Nanthakumar, P., 2020. Effect of process parameters on machining of Al-TiC metal matrix composites using RSM. Materials Today: Proceedings. DOI: 10.1016/j.matpr.2020.11.357.

[23] Lakshmi, K. J., Sogalad, I., Basavarajappa, S., \& Raghavendra, C. R. 2021., Optimization of erosive wear parameters on NiCrAlY based nano composite coating by RSM. Materials Today: Proceedings, 46: 763-766. 